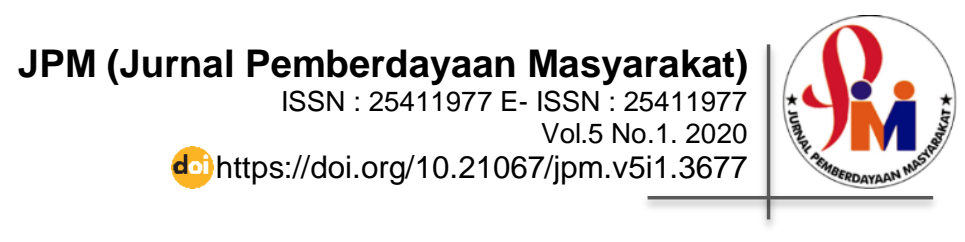

\title{
Pembuatan Laboratorium Media Berbasis Lingkungan dan Keunggulan Lokal Kudus
}

\author{
Himmatul Ulya ${ }^{*}$, Sekar Dwi Ardianti ${ }^{2}$ \\ Universitas Muria Kudus ${ }^{1,2}$ \\ himmatul.ulya@umk.ac.id*, sekar.dwi.ardianti@umk.ac.id
}

\begin{abstract}
The existence of a laboratory in Primary School 4 Karangbener (SD 4 Karangbener) was not used for learning but was converted into a warehouse. Lack of knowledge and skills of teachers and students in utilizing the environment and local superiority of Kudus to develop learning media and Mathematics and Natural sciences games cause a lack of media availability. This causes the teacher to dominate the implementation of learning so that student learning activities become low. The purpose of this mentoring activity is to design a laboratory that is available to be an environmentally based Mathematics and Natural Sciences media laboratory and Kudus local excellence. It aims to improve teacher skills in developing learning media and Mathematics and Natural Sciences games and student learning activities. The method used in this activity is to provide interactive training and mentoring. The results of this activity are that teachers and students can create and use learning media and games for Mathematics and Natural Sciences based on Kudus local excellence, teachers can reconstruct laboratory space and can utilize laboratory space through the implementation of Mathematics and Natural Sciences learning.
\end{abstract}

Keywords: Environment; Local Wisdom; Matthematics; Media of Laboratory; Science.

\begin{abstract}
Abstrak
Keberadaan laboratorium di Sekolah Dasar 4 Karangbener tidak dimanfaatkan untuk pembelajaran tetapi dialihfungsikan sebagai gudang. Kurangnya pengetahuan dan keterampilan guru dan siswa dalam memanfaatkan lingkungan dan keunggulan lokal Kudus untuk mengembangkan media pembelajaran dan permainan Matematika dan IPA menyebabkan kurangnya ketersediaan media. Hal ini menyebabkan guru mendominasi pelaksanaan pembelajaran sehingga aktivitas belajar siswa menjadi rendah. Tujuan dari kegiatan pendampingan ini adalah mendesain laboratorium yang tersedia menjadi laboratorium media Matematika dan IPA berbasis lingkungan dan keunggulan lokal Kudus. Hal ini bertujuan untuk meningkatkan keterampilan guru dalam mengembangkan media pembelajaran dan permainan Matematika dan IPA serta aktivitas belajar siswa. Metode yang digunakan dalam kegiatan ini adalah dengan memberikan pelatihan interaktif dan pendampingan. Hasil kegiatan ini yaitu guru dan siswa dapat membuat dan menggunakan media pembelajaran dan permainan Matematika dan IPA berbasis lingkungan dan keunggulan lokal Kudus, guru dapat merekonstruksi ruang laboratorium dan dapat memanfaatkan ruang laboratorium melalui implementasi pembelajaran Matematika dan IPA.
\end{abstract}

Kata Kunci: IPA; keunggulan lokal Kudus; Laboratorium media; Lingkungan, Matematika 


\section{A. PENDAHULUAN}

Gimin dan Kartikowati (2013) menyatakan bahwa kondisi dan suasana ruang belajar memiliki pengaruh positif terhadap motivasi belajar. Fakta di lapangan menunjukkan bahwa suasana pembelajaran dan ruang belajar Matematika dan Ilmu Pengetahuan Alam (IPA) di Sekolah Dasar membuat siswa bosan dan kurang berminat untuk belajar.

Penggunaan laboratorium media Matematika dan IPA merupakan salah satu inovasi dalam menciptakan ruang dan suasana belajar yang menyenangkan. Wiyanto et al. (2014) menyimpulkan bahwa apabila laboratorium dapat difungsikan dengan baik maka akan mendukung keberhasilan pembelajaran. Namun keberadaan laboratorium media Matematika dan IPA di Sekolah Dasar (SD) dianggap tidak biasa. Hal ini bertolak belakang dengan Peraturan Menteri Pendidikan Nasional Republik Indonesia No. 24 Tahun 2007 tentang Standar Sarana dan Prasarana untuk Sekolah Dasar/Madrasah Ibtidaiyah, setiap satuan pendidikan wajib memiliki prasarana berupa ruang laboratorium (Permendiknas, 2007).

Pembelajaran Matematika dan IPA yang dilakukan guru selama ini bersifat monoton. Menurut Ulya (2016), pembelajaran matematika yang kurang bervariasi, tidak kontekstual, dan masih bersifat abstrak dapat menyebabkan matematika menjadi momok bagi siswa sehingga tidak senang dan kesulitan dalam belajar. Putri (2014) menyimpulkan bahwa rendahnya minat belajar siswa dalam pelajaran IPA disebabkan karena kurangnya guru dalam menggunakan alat peraga. Mulyani (2013) mengemukakan bahwa media pembelajaran dapat digunakan untuk memperjelas materi agar mudah dipahami oleh siswa. Namun dalam implementasinya masih terdapat berbagai masalah dalam penyediaan dan penggunaan media untuk menunjang proses pembelajaran Matematika dan IPA.

Ardianti, Wanabuliandari, dan Rahardjo (2017) menyatakan bahwa proses pembelajaran yang dilakukan guru diharapkan dapat menyenangkan bagi siswa. Hal ini bisa dilakukan melalui pembelajaran dengan berbantuan media pembelajaran atau permainan karena membantu siswa dalam mengkonstruk pengetahuan sehingga siswa tidak secara instan menerima konsep saja tetapi ikut terlibat dalam penemuan pengetahuan.

Secara umum keberadaan laboratorium di sekolah belum dapat difungsikan dengan baik. Laboratorium media seharusnya dapat dirancang untuk membangun suasana dan ruang belajar Matematika dan IPA menjadi menyenangkan. Penggunaan media berbasis lingkungan dan berbasis keunggulan lokal dapat melatih siswa untuk lebih mencintai lingkungan dan mengenal keunggulan lokal di daerahnya. Media dapat digunakan untuk mempelajari konsep matematika yang bersifat abstrak dan memvisualisasikan konsep-konsep dalam IPA. Annisah (2014) menyatakan bahwa media pembelajaran seperti alat peraga merupakan suatu perangkat benda konkret yang dirancang, dibuat, dan disusun untuk membantu menanamkan dan memahami konsep-konsep dalam matematika.

SD 4 Karangbener terletak di Kecamatan Bae, Kabupaten Kudus. Kondisi SD dekat dengan perkampungan dan persawahan dimana banyak potensi lingkungan yang dapat dijadikan sumber belajar. Sekolah ini telah memiliki ruang laboratorium yang belum difungsikan dengan baik. Ruang laboratorium yang tersedia 
dialihfungsikan sebagai gudang penyimpanan.

Selama ini guru di SD 4 Karangbener tidak memanfaatkan media permainan dalam pembelajaran Matematika maupun IPA karena kurangnya pengetahuan dan keterampilan guru dalam membuat dan menggunakan media. Hanya $30 \%$ guru yang dapat mengintegrasikan macam-macam media dengan materi Matematika/IPA. Guru beranggapan bahwa ketika membuat media pembelajaran memerlukan bahan yang mahal dan sulit ditemukan. Padahal media pembelajaran dapat dibuat secara sederhana dengan memanfaatkan lingkungan sekitar dan keunggulan lokal Kudus.

Siswa di SD 4 Karangbener yang mayoritas berasal dari pedesaan memiliki karakteristik sopan tetapi kurang peduli dengan lingkungan sekitar. Indikasi ini dibuktikan dengan banyak dijumpai bungkus sisa makanan ringan di sekitar kantin sekolah. Pengetahuan akan keunggulan lokal Kudus siswa di SD 4 Karangbener juga rendah. Berdasarkan penilaian angket dan wawancara, hanya $21 \%$ siswa dari kelas tinggi yang mampu menyebutkan beberapa keunggulan lokal Kudus.

Guru dan siswa SD 4 Karangbener belum dapat memanfaatkan lingkungan dan keunggulan lokal sebagai sumber belajar. Kertas atau sampah plastik yang merupakan limbah dari sekolah seyogyanya dapat dimanfaatkan untuk media pembelajaran. Fakhriyah, Wanabuliandari, dan Ardianti (2016) menyatakan bahwa dengan pemanfaatan sampah plastik dan kertas untuk media pembelajaran inovatif dapat meningkatkan kreativitas dan kepedulian terhadap lingkungan. Hal tersebut ditegaskan oleh Ardianti, Wanabuliandari, dan Rahardjo (2017) bahwa dengan pemanfaatan lingkungan siswa dapat mengetahui secara langsung kondisi nyata lingkungan sehingga dapat memberikan pengetahuan dan pengalaman bagi siswa secara nyata. Kudus memiliki beragam keunggulan lokal seharusnya juga dapat dimanfaatkan sebagai media pembelajaran Matematika dan IPA. Ulya dan Rahayu (2017) menyatakan bahwa pembelajaran berbasis keunggulan lokal yaitu dengan memanfaatkan media berbasis keunggulan lokal dapat meningkatkan kemampuan matematis siswa dan menurunkan kecemasan matematika siswa.

Berdasarkan permasalahan tersebut perlu adanya solusi untuk mengatasi permasalahan pembelajaran Matematika dan IPA di SD 4 Karangbener. Hal ini dilakukan dengan memberikan pendampingan perekonstruksian laboratorium media Matematika dan IPA agar dapat menciptakan suasana belajar Matematika dan IPA yang menyenangkan. Harapannya siswa dapat melakukan dapat eksplorasi, penemuan, dan menumbuhkan ketertarikan terhadap pelajaran Matematika dan IPA. Selain itu, diharapkan juga dapat mengembangkan profesionalisme guru yang akan berdampak pada peningkatan kualitas pembelajaran.

\section{B. PELAKSANAAN DAN METODE}

Kegiatan ini dilaksanakan di SD 4 Karangbener Kudus. Kegiatan ini meliputi tahap observasi awal, perencanaan, pelaksanaan, dan evaluasi. Metode pelaksanaan kegiatan pendampingan ini menggunakan pendekatan participant active learning (peserta berpartisipasi secara aktif dalam kegiatan pendampingan). Kegiatan ini berbentuk pelatihan interaktif dan pendampingan sehingga terjadi interaksi dua arah antara tim dan peserta kegiatan. Hal ini bertujuan agar peserta pendampingan (guruguru dan siswa-siswi SD 4 Karangbener Kudus) dapat saling bertukar ilmu, ide, pikiran, pendapat, dan pengalamannya 
sehingga akan memperoleh ilmu yang bermanfaat untuk pembelajaran Matematika dan IPA. Di dalam proses pelatihan dan pendampingan, menggunakan metode ceramah, tanya jawab, diskusi, penemuan, simulasi, dan praktik.

\section{HASIL DAN PEMBAHASAN}

\section{Tahap Observasi Awal}

Tahap observasi awal dilakukan untuk menganalisis situasi dengan cara observasi lapangan dan wawancara baik dari kondisi lingkungan, ketersediaan laboratorium media Matematika dan IPA, permasalahan guru, dan siswa di SD 4 Karangbener Kudus dalam pembelajaran Matematika dan IPA. Laboratorium di SD 4 Karangbener dialihfungsikan sebagai gudang untuk penyimpanan barang yang tidak terpakai. Kondisi laboratorium disajikan pada Gambar 1 berikut ini.

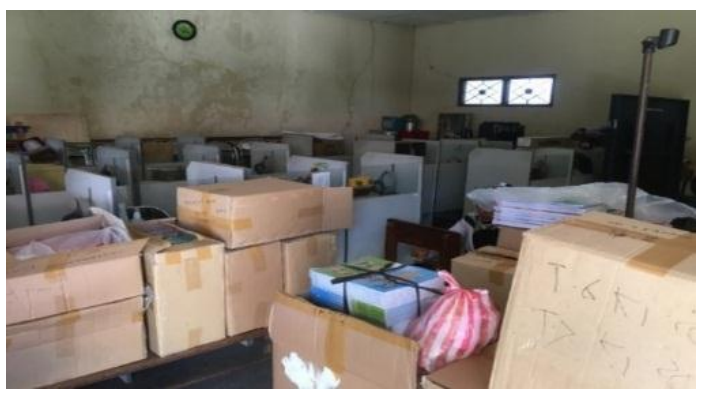

Gambar 1. Laboratorium SD 4 Karangbener

\section{Tahap Perencanaan}

Pada tahap perencanaan, tim melakukan perizinan, analisis kebutuhan sarana di laboratorium, mendiskusikan jenis media yang akan dikembangkan, dan menyusun buku panduan. Langkah pertama dalam kegiatan perencanaan yaitu tim melakukan perizinan dan koordinasi kepada kepala sekolah mitra yaitu SD 4 Karangbener Kudus. Kepala sekolah menyambut positif kegiatan ini karena terbantu untuk memecahkan masalah laboratorium yang tidak difungsikan dengan baik.

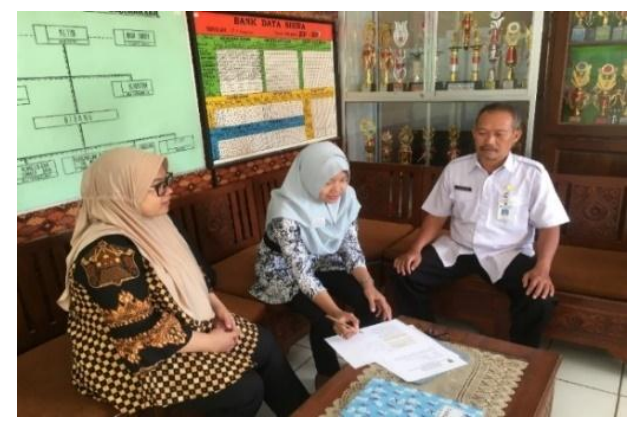

Gambar 2. Perizinan dengan Kepala SD 4 Karangbener

Setelah melakukan perizinan, analisis kebutuhan sarana laboratorium SD 4 Karangbener dilakukan oleh tim bersama guru-guru di SD 4 Karangbener. Berdasarkan hasil analisis ditemukan bahwa sarana yang diperlukan yaitu media pembelajaran dan permainan Matematika dan IPA berbasis lingkungan dan keunggulan lokal Kudus, almari penyimpanan media, meja, kursi, papan tulis, alat tulis, dan lain-lain. Kemudian tim melakukan studi literatur dan Focus Group Discussion (FGD) untuk mendiskusikan jenis media yang sesuai dengan kebutuhan siswa dan materi. Selain itu, media yang dibuat disesuaikan dengan lingkungan dan keunggulan lokal Kudus. Kegiatan tersebut ditindaklanjuti dengan melakukan penyusunan buku panduan pemanfaatan lingkungan dan keunggulan lokal Kudus sebagai media pembelajaran.

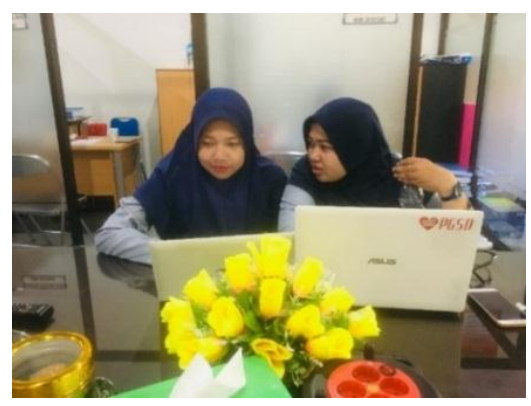

Gambar 3. Kegiatan Penyusunan Buku Panduan Praktis 


\section{Tahap Pelaksanaan}

Tahap ini tim memberikan pendampingan pembuatan dan penggunaan media pembelajaran dan media berbasis lingkungan dan keunggulan lokal Kudus. Kegiatan pendampingan diawali dengan sosialisasi. Materi sosialisasi meliputi bahanbahan dari lingkungan sekitar yang dapat digunakan sebagai media pembelajaran Matematika dan IPA, macam-macam keunggulan lokal Kudus yang dapat digunakan sebagai media pembelajaran, serta cara pembuatan dan penggunaan media pembelajaran Matematika dan IPA. Pendampingan terhadap guru dalam mendesain, membuat, dan menggunakan media pembelajaran dan media permainan berbasis lingkungan dan keunggulan lokal Kudus.

Setelah pemberian materi awal pendampingan, tim melaksanaan pendampingan pembuatan dan penggunaan media. Suasana pada saat pendampingan pembuatan media disajikan pada gambar berikut.

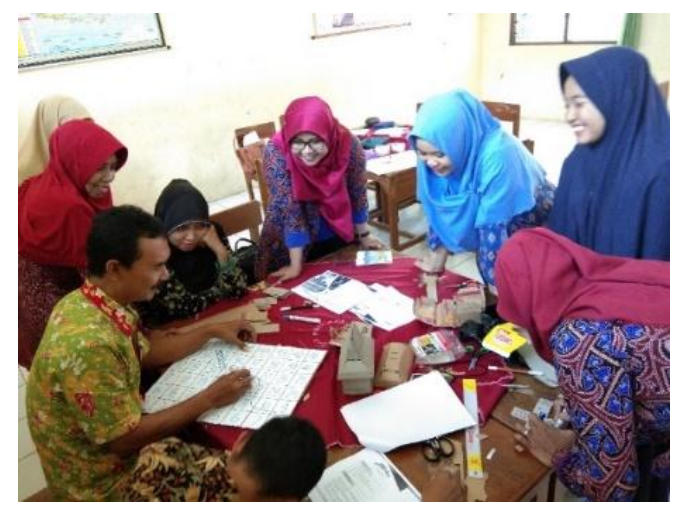

Gambar 4. Pendampingan Pembuatan Media

Peserta pendampingan sangat interaktif dan antusias dalam pendampingan penggunaan media pembelajaran dan media permainan ini. Penggunaan media pembelajaran Matematika dan IPA berbasis lingkungan dan keunggulan lokal Kudus merupakan pengetahuan baru bagi guru di SD 4 Karangbener Kudus. Setelah mengetahui cara pengggunaan media pembelajaran dan media permainan, guru dapat mengimplementasikan dalam simulasi pembelajaran seperti pada gambar berikut.

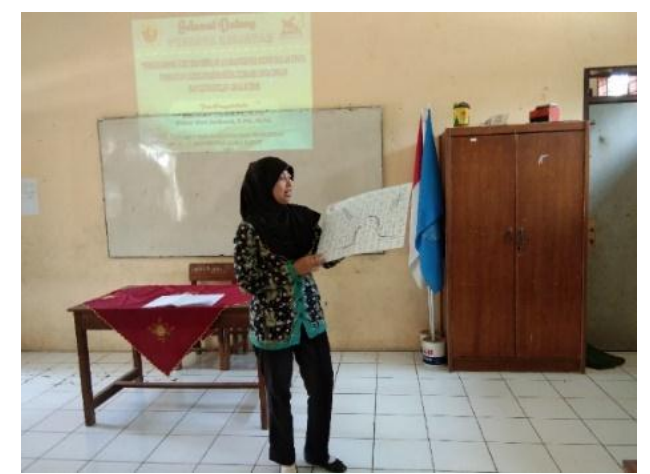

Gambar 5. Pendampingan Simulasi Pembelajaran IPA Menggunakan Media Pembelajaran dan Permainan

Pada tahap simulasi, peserta melakukan simulasi mengajar Matematika dan IPA SD berbantuan media pembelajaran dan media permainan berbasis lingkungan dan keunggulan lokal Kudus di depan teman sejawat dan tim.

Selain melakukan pendampingan untuk guru, tim juga melakukan pendampingan terhadap siswa dalam membuat, dan menggunakan media pembelajaran berbasis lingkungan dan keunggulan lokal Kudus. Tim mengawali pendampingan dengan mengenalkan siswa terhadap keungulan lokal Kudus dan mengenalkan sumber-sumber belajar mata pelajaran Matematika dan IPA yang berasal dari lingkungan dan keunggulan lokal Kudus. Pada tahap ini, tim berperan sebagai guru untuk memberikan tugas proyek kepada siswa. Siswa berkelompok mendiskusikan dan membuat tugas proyek. Siswa mendesain dan membuat media pembelajaran dan media permainan Matematika dan IPA. Hal ini disajikan pada Gambar 6. 


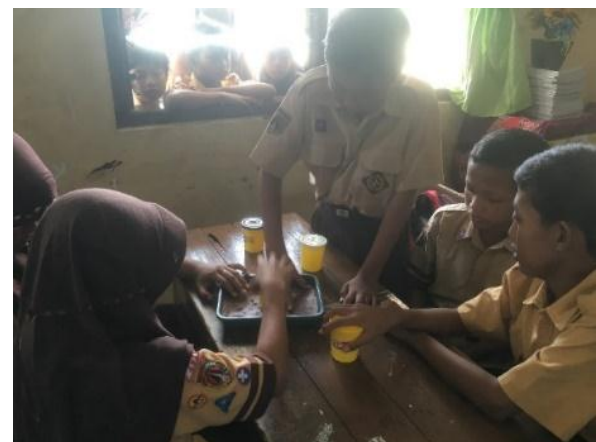

Gambar 6. Siswa Berkelompok untuk Membuat Media Pembelajaran

Dalam melakukan kegiatan pendesainan dan pembuatan media pembelajaran dan media permainan Matematika dan IPA berbasis lingkungan dan keunggulan lokal Kudus siswa sanat antusias dan bersemangat. Kegiatan ini dapat membuat siswa untuk terlibat langsung di dalam mempelajari konsep dan memecahkan masalah sehingga aktivitas siswa dalam pembelajaran semakin meningkat. Selain dapat membuat, siswa juga dibimbing untuk dapat menggunakan media yang dibuat. Produk media hasil kerja setiap kelompok kemudian disajikan penggunaannya di depan kelas.

Kegiatan selanjutnya yaitu perekonstruksian laboratorium diawali koordinasi dengan kepala SD 4 Karangbener, wakil kepala sekolah bagian sarana dan prasarana, penjaga sekolah, dan tim untuk mengecek kondisi terbaru dari ruangan. Kegiatan koordinasi ini juga membahas perlengkapan dan keperluan sarana yang dibutuhkan ruangan laboratorium sehingga nantinya akan layak menjadi laboratorium media Matematika dan IPA. Ruang laboratorium memerlukan sarana seperti meja, papan tulis, almari penyimpanan media, karpet, dan lain-lain. Laboratorium direnovasi dan dicat ulang untuk kenyamanan belajar siswa. Selanjutnya, tim memberikan pendampingan pengaturan laboratorium media Matematika dan IPA agar dapat menciptakan suasana belajar Matematika dan IPA yang menyenangkan. Guru didampingi oleh tim untuk menata ruangan sekaligus media pembelajaran yang telah dikembangkan. Kegiatan pendesainan dan perekonstruksian agar tertata dengan rapi sekaligus dapat menciptakan kesan menarik pada laboratorium. Guru juga dapat memberikan masukan kepada tim mengenai pendesainan ruangan laboratorium.

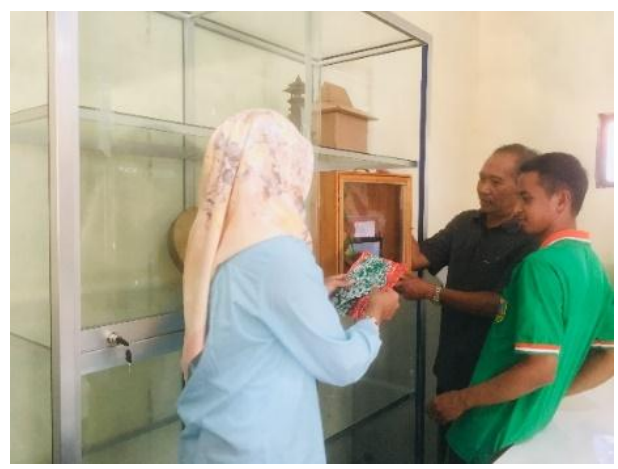

Gambar 7. Penataan Media Pembelajaran oleh Guru

Setelah laboratorium direkonstruksi, guru diberikan pendampingan mengenai pemanfaatan ruang laboratorium melalui pendampingan implementasi pembelajaran Matematika dan IPA menggunakan ruang laboratorium. Tim mendampingi guru melakukan pembelajaran dengan memanfaatkan ruang laboratorium.

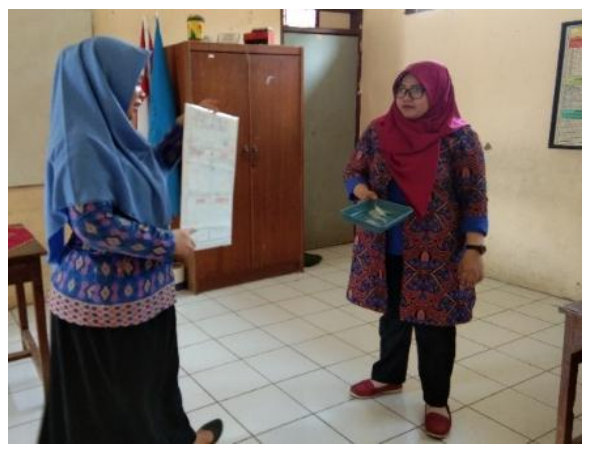

Gambar 8. Implementasi Pembelajaran Menggunakan Media Pembelajaran 
Dalam pembelajaran, siswa difasilitasi dalam kegiatan praktikum sehingga aktivitas belajar dan pemahaman konsep siswa meningkat. Penggunaan media berbasis lingkungan dan berbasis keunggulan lokal sebagai sumber belajar dapat melatih siswa untuk lebih mencintai lingkungan dan mengenal keunggulan lokal di daerahnya. Sebagai keberlanjutan program kegiatan, guru yang akan menggunakan ruang laboratorium harus berkoordinasi dengan koordinator laboratorium yang ditunjuk oleh kepala SD 4 Karangbener.

\section{Tahap Evaluasi Kegiatan}

Tim melakukan evaluasi antara tim dengan mitra untuk mengetahui keefektifan dan efisiensi dari kegiatan yang sudah dilaksanakan. Hasil evaluasi menunjukkan bahwa guru memiliki pengetahuan dan keterampilan $93 \%$ untuk membuat media dan menggunakan media pembelajaran. Siswa memiliki pengetahuan dan keterampilan $88 \%$ untuk membuat media dan menggunakan media pembelajaran. Selain itu sebanyak $80 \%$ siswa telah aktif dalam pembelajaran dan seluruh siswa dilibatkan dalam kegiatan praktikum Matematika maupun IPA.

\section{PENUTUP}

\section{Simpulan}

Simpulan dari kegiatan ini yaitu kegiatan ini dilakukan melalui tahap observasi awal, perencanaan, pelaksanaan, dan evaluasi. Tahap observasi awal dengan melakukan analisis situasi dengan cara observasi lapangan dan wawancara baik dari kondisi lingkungan, ketersediaan laboratorium media Matematika dan IPA serta media pembelajaran dan media permainannya, permasalahan guru, dan kesulitan siswa di SD 4 Karangbener Kudus dalam pelaksanaan pembelajaran Matematika dan IPA.
Tahap perencanaan meliputi perizinan kepada kepala SD 4 Karangbener Kudus, pengidentifikasian kebutuhan sarana laboratorium, studi literatur untuk mengembangkan media, FGD untuk mendiskusikan jenis media yang sesuai dengan kebutuhan siswa dan materi, melakukan penyusunan buku panduan praktis pemanfaatan lingkungan dan keunggulan lokal Kudus sebagai media pembelajaran.

Tahap pelaksanaan dilakukan dengan memberikan pendampingan pembuatan dan penggunaan media melalui sosialisasi mengenai bahan-bahan dari lingkungan sekitar yang dapat digunakan sebagai media pembelajaran, macam-macam keunggulan lokal Kudus yang dapat digunakan sebagai media pembelajaran, pendampingan terhadap guru dan siswa dalam mendesain, membuat, dan menggunakan media pembelajaran dan media permainan berbasis lingkungan dan keunggulan lokal Kudus, perekonstruksian ruangan laboratorium, dan pemanfaatan ruang laboratorium melalui pendampingan implementasi pembelajaran Matematika dan IPA.

Tahap evaluasi menunjukkan hasil bahwa guru memiliki pengetahuan dan keterampilan 93\% untuk membuat media dan menggunakan media pembelajaran. Siswa memiliki pengetahuan dan keterampilan $88 \%$ untuk membuat media dan menggunakan media pembelajaran. Selain itu sebanyak $80 \%$ siswa telah aktif dalam pembelajaran dan seluruh siswa dilibatkan dalam kegiatan praktikum Matematika maupun IPA.

\section{Saran}

Laboratorium media berbasis lingkungan dan keunggulan lokal Kudus merupakan keunggulan yang dimiliki SD 4 Karangbener sehingga sebagai keberlanjutan program, pihak sekolah dapat membagi pengalaman hasil pendampingan kepada guru- 
guru di SD lain melalui kegiatan Kelompok Kerja Guru (KKG). Kegiatan ini bertujuan untuk menciptakan inovasi pembelajaran Matematika dan IPA melalui penggunaan laboratorium media Matematika dan IPA berbasis lingkungan dan keunggulan lokal Kudus.

\section{Ucapan Terima Kasih}

Terima kasih kepada DRPM Ristek Dikti yang telah memberikan hibah Program Kemitraan Masyarakat. Selain itu ucapan terima kasih disampaikan kepada kepala sekolah, guru-guru, siswa-siswi SD 4 Karangbener, dan berbagai pihak yang terlibat.

\section{E. DAFTAR PUSTAKA}

Annisah, S. 2014. Alat Peraga Pembelajaran Matematika. Jurnal Tarbawiyah, 11(1): $1-15$.

Ardianti, S.D., Wanabuliandari, S., dan Rahardjo, S. 2017. Peningkatan Perilaku Peduli Lingkungan dan Tanggung Jawab Siswa Melalui Model EJAS Dengan Pendekatan Science Edutainment. Jurnal Pendidikan Dasar. 4(1): 1-7.

Fakhriyah, F., Wanabuliandari, S., dan Ardianti, S.D., 2016. Pendampingan Pemanfaatan Sampah Plastik dan Kertas untuk Media Pembelajaran Inovatif Bagi Guru Di SDN 5 Bae Kudus. Jurnal Pengabdian Pada Masyarakat. 1(1):4855.

Gimin dan Kartikowati, S. 2013. Analisis Faktor yang Mempengaruhi Motivasi Belajar Mahasiswa Program Studi Pendidikan Ekonomi FKIP Universitas Riau. Jurnal Pendidikan, 4(1): 1-14.
Mulyani, S. 2013. Pembelajaran Matematika dengan Alat Peraga Papan Berpasangan. E-Jurnal Dinas Pendidikan Kota Surabaya, 5: 1-11.

Peraturan Menteri Pendidikan Nasional Republik Indonesia No. 24 Tahun 2007 tentang Standar Sarana dan Prasarana untuk Sekolah Dasar/Madrasah Ibtidaiyah (SD/MI). Jakarta: Depdiknas.

Putri, N. 2014. Meningkatkan Hasil Belajar IPA dengan Menggunakan Model Pembelajaran Kooperatif Tipe Snowball Throwing di Kelas V SD. School Education Journal, 1(1): 78-83.

Ulya, H. 2016. Pembelajaran Matematika Berbasis Etnomatematika untuk Membangun Karakter Cinta Tanah Air dan Kreativitas Belajar Matematika. Prosiding Seminar Nasional Psikologi Universitas Muria Kudus: 29-39.

Ulya, H., dan Rahayu, R. 2017a. Efektivitas Pembelajaran Probing-Prompting Berbasis Etnomatematika Terhadap Kemampuan Literasi Matematika. Jurnal Edudikara, 2(4): 315-323.

Ulya, H., dan Rahayu, R. 2017b. Pembelajaran Etnomatematika Untuk Menurunkan Kecemasan Matematika. Jurnal Mercumatika, 2(1): 16-23.

Wiyanto, Cahyono, E., Suwarsi, E., Soedjoko, E., dan Parmin. 2014. Persepsi Guru Tentang Fungsi Laboratorium dalam Pembelajaran Matematika dan IPA. Prosiding Seminar Nasional Konservasi dan Kualitas Pendidikan: 28-38. 